\title{
El hispanoamericanismo de Silvio Zavala como fuente de inspiración*
}

\author{
Óscar Mazin ***
}

A Erika Pani

Quiero empezar estas palabras expresando mi reconocimiento al jurado convocado por el Instituto Panamericano de Geografía e Historia (IPGH), que me atribuyó el Premio "Silvio Zavala”, edición de 2018, por mi trayectoria en la disciplina de Historia de América Colonial. Soy consciente de la trascendencia de este galardón, tanto en lo tocante al Instituto, organismo especializado fundado en 1928, hace precisamente 90 años y ulteriormente adscrito a la Organización de Estados Americanos (OEA). Pero también en lo concerniente a su Comisión de Historia, misma que, establecida desde 1946, tuvo como su primer director precisamente a don Silvio Arturo Zavala Vallado. La instalación de esa comisión, que hoy encabeza dignamente la doctora Patricia Galeana, fue todo un acontecimiento en los anales de la historiografía de México y del resto de Hispanoamérica, pues nació con una vocación internacional. ${ }^{1}$ Vocación estimulada desde 1938 por la Revista de

* Este documento fue leído por el autor en la entrega del Premio a la trayectoria académica "Silvio Zavala" en Historia Colonial de América, edición 2018.

** El Colegio de México, correo electrónico: mazin@colmex.mx

Expreso mi gratitud a mis amigas Roxana Álvarez Nieves y Yazmín Jimeno por su ardua labor en la integración de mi expediente para el Premio Silvio Zavala.

1 En la IV Asamblea del Instituto, celebrada en Caracas, el gobierno de México se comprometió a instalar la Comisión de Historia por medio del Instituto Nacional de Antropología e Historia que entonces dirigía el arquitecto Ignacio Marquina. Se nombró a Zavala, por entonces director del Museo Nacional de Historia, como miembro nacional ante dicha comisión. Luego, el IPGH eligió a don Silvio como presidente interino de dicha Comisión de Historia. Remito a Roberto Fernández Castro, "Silvio Zavala y la historiografía americana. Una vida de vínculos intelectuales”, Revista de Historia de América, núm. 155, nueva época, julio-diciembre, 2018. 
Historia de América, fundada por el propio Zavala como órgano científico del Instituto que hoy me otorga este importante reconocimiento. ${ }^{2}$

Vi a don Silvio y hablé brevemente con él en tres ocasiones: cuando en 1977 me obsequió, autografiado, un ejemplar de su libro América en el espíritu francés del siglo XVIII. Era yo entonces un estudiante de licenciatura en el Departamento de Historia de la Universidad Iberoamericana. Nuestra segunda comunicación tuvo lugar una década más tarde, en ocasión del X aniversario de El Colegio de Michoacán, en enero de 1989. Me conmueven aún las palabras con que el doctor Zavala exaltó el papel de las ciudades en la forja de la civilización occidental y la relevancia que toda gran urbe desempeña, como maestra de la vida, en la formación de los historiadores. Finalmente le expresé a don Silvio mi agradecimiento por una carta que él envió a mi profesor, ahora colega y sobre todo amigo, Andrés Lira González, quien años antes me había acogido en el Programa de Maestría en Historia de El Colegio de Michoacán. En esa misiva, don Silvio le manifestaba su agrado por la aparición de los dos volúmenes de la Guía e inventario del Archivo del Cabildo Catedral Metropolitano de México, empresa que me tocó dirigir en los años de 1998 y $1999 .{ }^{3}$ Sigo valorando ese agrado del doctor Zavala. Su sensibilidad para el rescate de los archivos de las iglesias catedrales arraiga en uno de los más sólidos estratos de sus afanes históricos, la historia del trabajo y de las formas sociales de sujeción. De hecho, su obra más ingente, las fuentes para la historia del trabajo en Nueva España, consiste en un rescate y acopio documental de dimensiones titánicas. Fruto de ese esfuerzo de décadas es un precioso librito titulado Una etapa en la construcción de la catedral de México alrededor de $1585 .{ }^{4}$ Con razón mi colega y amiga, la historiadora de arte Nelly Sigaut, escogió un fragmento de ese texto de Zavala para epígrafe del libro que coordinó y editó, La catedral de Morelia, donde se recogen las fuentes primordiales de la construcción de esa

2 Remito a los trabajos de Andrés Lira "Revolución y Constitución en la obra de Silvio Zavala, 1930-1932”, Roberto Fernández Castro “Silvio Zavala y la historiografía americana. Una vida de vínculos intelectuales" y Erika Pani, "Silvio Zavala y la historia de América. Un juego de escalas” publicados en el número antes citado de la Revista de Historia de América...pp. 13-32; 33-56 y 177-192. Este texto está también en deuda con la semblanza de Silvio Zavala y su obra presentada por Rodrigo Martínez Baracs en ocasión del homenaje que organizó la Universidad de Guadalajara el 18 de octubre de 2018.

3 Óscar Mazín (dir.), Archivo del Cabildo Catedral Metropolitano de México. Inventario y guía de acceso, México, El Colegio de Michoacán, Centro de Estudios de Historia de México-Condumex, 1999, 2 vols.

4 Silvio Zavala, Una etapa en la construcción de la catedral de México alrededor de 1585, México, El Colegio de México, El Colegio Nacional, 1995. [1ª edición, 1982]. 
iglesia, testimonios que años antes habíamos rescatado y organizado con el patrocinio de El Colegio de Michoacán. ${ }^{5}$

Con todo, lo que más me entusiasma e inspira de la obra de Silvio Zavala es su valiente apuesta por el horizonte americano e hispanoamericano en particular, cuando predominaba una historia estrictamente nacional en la concepción de la mayoría de los programas de estudios. Durante décadas, porfiadamente leímos en éstos, el anacrónico título "Curso de México colonial”. Poco antes de doctorarme, en 1995, había yo leído con delectación La España imperial de John H. Elliott, libro cuya trascendencia no fue debidamente aquilatada en México sino precisamente a partir de aquella década no obstante haberse publicado desde $1963 .{ }^{6}$ Concebido por su autor como manual a partir de su experiencia docente, me convenció de que para hacer historia en nuestro país no se puede prescindir de la escala de las Monarquías de España y Portugal como entidades compuestas de escala planetaria. Pero también es imprescindible restituir las formas de inserción, los vínculos de la Nueva España con ese su ámbito natural y no con el Estado-Nación. Tres de las responsabilidades académico administrativas que entonces asumí apuntaron en esa línea: convoqué a una sección temática de la revista Relaciones de El Colegio de Michoacán, intitulado: "La Monarquía española, grupos políticos locales ante la Corte de Madrid” (1998); ${ }^{7}$ traduje al español y edité en esa misma revista el artículo "La historia comparativa", de John H. Elliott; ${ }^{8}$ finalmente organicé y edité un coloquio llamado México en el mundo hispánico (2000). ${ }^{9}$

Mi convicción de que somos herederos y artífices de las tradiciones humanísticas se acrecienta cada vez más, son ellas el fondo de nuestros sueños, trabajos y días. Luego de ser contratado como profesor por El Colegio de México en el año 2000, Javier Garciadiego, entonces director de su Centro de Estudios Históricos, me pidió servir de mediador con la Biblioteca Daniel Cosío Villegas. Debo aquí hacer una digresión para expresar el honor y orgullo que siento de haber sido acogido en ese claustro fundado en 1941 por Silvio Zavala a inspiración del viejo Centro de Estudios Históricos de Madrid. No es de extrañar, pues don Silvio se contó entre los miembros de la Casa de España al lado de Alfonso Reyes. Dicho sea de paso, este último no sólo había exhortado a Zavala a reforzar las investigaciones hispanoameri-

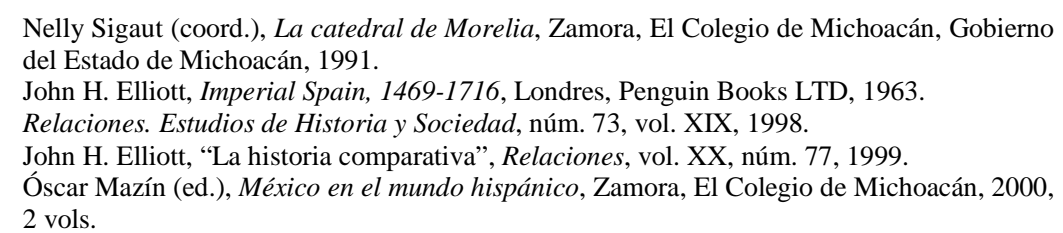


canas en México, sino a asumir la elaboración de una historia de América. Para cerrar esta digresión también deseo evocar la convicción con que expresé a don Luis González y González, autor de "La pasión del nido", la continuidad que para mí suponía, y supone, haber volado a ese nido, es decir a El Colegio de México, luego de haberme formado como investigador en Zamora con él mismo, con Andrés Lira, Carlos Herrejón, Jean Meyer, Heriberto Moreno, Cecilia Noriega y demás maestros fundadores del primer Colegio de Posgrado en Historia y Ciencias Sociales fuera de la capital del país. ${ }^{10}$

En la estela de mis años de doctorado en Francia, bajo la dirección de Jean-Pierre Berthe, guarda gran relevancia mi maestra, la medievalista Adeline Rucquoi, quien me familiarizó con las tres grandes figuras del medievalismo hispano: Ramón Menéndez Pidal, Américo Castro y Claudio Sánchez Albornoz. En los primeros años de la década de 1930 Silvio Zavala se benefició en persona de su saber; tan es así que Menéndez Pidal, director del Centro de Estudios Históricos de Madrid, lo acogió en esa Casa y Américo Castro fue lector de su manuscrito Las Instituciones jurídicas en la conquista de América. Éste es un libro publicado en 1935 por la Sección Hispanoamericana de dicho Centro de Estudios madrileño a la que don Silvio se había incorporado en 1933. Historiador fincado en el derecho, Zavala concibe las "instituciones" como dinámicas, es decir, a la vez como cuerpos y como mecanismos integradores de conductas y acciones sociales.

Del legado medieval debo destacar la importante renovación historiográfica propuesta en 1992 por Adeline Rucquoi, heredera intelectual de Claudio Sánchez Albornoz. Y lo hago en razón de un texto seminal suyo publicado en 1992 en la revista Relaciones, es decir, en los odres de la tradición de Silvio Zavala y de Luis González. "De los reyes que no son taumaturgos, los fundamentos de la realeza en España", ha sido un artículo muy fecundo. ${ }^{11}$ En diálogo crítico con la escuela de la revista Annales, Rucquoi nos convence de la necesidad de hurgar en las continuidades del tiempo largo según el cual las Indias de Castilla resultaron todo, menos ajenas al largo pasado "medieval" ibérico que nunca fue marginal respecto de Europa central, en discrepancia con las enseñanzas de los grandes medievalistas nórdicos de principios del siglo $\mathrm{XX}$.

10 Luis González y González, “La pasión del nido”, Historia Mexicana, vol. 25, núm. 4 (100), 1976, pp. 530-598.

11 Adeline Rucquoi, "De los Reyes que no son taumaturgos: los fundamentos de la realeza en España”, Relaciones, vol. XIII, núm. 51, 1992, pp. 55-100. Nelly Sigaut coordinó y editó dicho número. 
Estimulado por el rastreo de esas continuidades y comisionado como estaba por mi centro de estudios ante la Biblioteca Cosío Villegas, me serví con cuchara grande. Emprendí la elaboración de un ensayo bibliográfico que llamé Una ventana al mundo hispánico, mismo que cuenta con dos volúmenes publicados y un tercero en preparación. ${ }^{12}$ Me guiaron dos propósitos: por un lado, aquilatar a los clásicos entre los que, desde luego, descuellan $L a$ encomienda indiana (1935) y El mundo americano en la época colonial (1967), de Silvio Zavala. Por sí solo, este último título demuestra la unidad de Hispanoamérica en términos de civilización. ${ }^{13} \mathrm{Mi}$ ensayo también hace acopio de las novedades de los últimos 20 años de una historiografía internacional decidida a tomar distancia de la historia nacional y a restituir los vínculos entre las muy diversas latitudes de las monarquías ibéricas, España y Portugal. ${ }^{14}$ En algún sentido, el ensayo quiere ser tributario de la propuesta que don Silvio hiciera en 1939 a Alfonso Reyes de crear una Biblioteca Latina Hispanoamericana. ${ }^{15}$

Como lo ha mostrado Andrés Lira en un afectuoso y reciente testimonio, "El tiempo español de Silvio Zavala" resultó definitivo. Convenció al jurista de formación de la hondura y de las continuidades de los tiempos históricos en ambas orillas del Atlántico. ${ }^{16}$ Bastaría con examinar, por ejemplo, sus "Conquistas de Canarias y de América", artículo temprano y pionero en que descuella su entusiasmo por el enfoque comparativo. ${ }^{17}$ Éste y El mundo Americano en la época colonial son elocuentes de que, marcada por su duración y su acción en profundidad, Iberoamérica es acaso la empresa histórica más colosal y original que pueblos del Occidente europeo hayan jamás emprendido en ultramar. Se trata de una herencia cultural que la independencia no pudo borrar. Poco después me esforcé en mostrar este aserto en un texto de difusión universitaria también salido de las prensas de El Colegio de

12 Óscar Mazín, Una ventana al mundo hispánico. Ensayo bibliográfico, México, El Colegio de México, 2006 (vol. I) y 2013 (vol. II).

13 En este libro Zavala, con la colaboración de María del Carmen Velázquez, recoge las conclusiones de numerosas monografías del programa de Historia de América del Instituto Panamericano de Geografía e Historia. Roberto Fernández Castro, "Silvio Zavala y la historiografía americana. Una vida de vínculos intelectuales”, Revista de Historia de América, núm. 155, 2018, p. 48.

14 Silvio Zavala, El mundo americano en la época colonial, México, Porrúa, 1967.

15 Roberto Fernández Castro, "Silvio Zavala y la historiografía americana. Una vida de vínculos intelectuales”, Revista de Historia de América, núm. 155, nueva época, 2018, p. 42.

16 Andrés Lira, "El tiempo español de Silvio Zavala: la vocación. Notas sobre un diálogo epistolar", en Aurelia Valero Pie, coordinadora y editora, Los empeños de una casa. Actores y redes en los inicios de El Colegio de México, México, El Colegio de México, 2015, pp. 77-94.

${ }^{17}$ Silvio Zavala, "Las conquistas de Canarias y América”, Tierra Firme I:4, 1935 pp. 81-112 y II:1, 1936, pp. 89-115. 
México, en 2007. Ahí intenté caracterizar los empalmes de una misma civilización, comparando los tres grandes núcleos de Nueva España, los Andes y el Brasil, éste por lo menos durante la unión de las Coronas ibéricas entre 1580 y1640. ${ }^{18}$

"El universo americano en las obras de Silvio Zavala", título de una conferencia impartida por Andrés Lira, da cuenta de que la historia llamada de las instituciones alude a cuadros o marcos coordinadores de procesos de integración y diferenciación del orden social en todas latitudes. Es decir, las entiende de acuerdo con el dinamismo de los procesos y no en términos simplemente formales, rígidos, o sea impermeables al devenir, al paso del tiempo, que es el meollo del oficio de historiar. Desde esta misma perspectiva intenté organizar el acopio ya mencionado de materiales bibliográficos. Una serie de ejes temáticos o hilos conductores articulan las referencias y las aglutinan a la vez según los procesos históricos en el tiempo largo de las sociedades hispánicas, desde la Antigüedad tardía hasta el siglo XVIII y aún más allá. Son, dichos ejes: la movilidad espacial y social a que tanto alude la parte más voluminosa de la obra de Zavala, la ya evocada historia del trabajo de los indios o Los intereses particulares en la conquista de la Nueva España, su tesis doctoral madrileña del año 1933; la impronta de las ciudades, tan definitiva en sus obras acerca de Vasco de Quiroga; el saber y la enseñanza por él estudiados en su Filosofía de la conquista (1947); el rey y sus jueces, es decir, el problema del jurisdiccionalismo que hoy tanto marca nuestros estudios y que La encomienda indiana prefiguró; finalmente la hispanización o cristianización, fenómeno subyacente en textos como Servidumbre natural y libertad cristiana según los tratadistas españoles de los siglos XVI y XVII. ${ }^{19}$

El más reciente número de la Revista de Historia de América reúne trabajos de homenaje a don Silvio Zavala en razón de este, el nonagésimo y feliz aniversario de ese órgano, lo que acrecienta mi satisfacción y gusto por la distinción que hoy recibo. Uno de los temas abordados en ese número es el que atañe a las posibilidades y oportunidades de escribir una historia del continente. Me parece que el problema medular de tamaña empresa radica en que no puede concebírsela para "escribir con mayor acierto las historias

18 Óscar Mazín, Iberoamérica. Del Descubrimiento a la Independencia, México, El Colegio de México, 2007.

19 Silvio Zavala, Los intereses particulares en la conquista de la Nueva España, Madrid, 1933. Filosofía de la conquista, México, Fondo de Cultura Económica, 1947 (Colección Tierra Firme). Servidumbre natural y libertad cristiana según los tratadistas españoles de los siglos XVI y XVII, Buenos Aires, Penser, 1944. 
nacionales". ${ }^{20}$ Dicho de otra manera, historiar los vínculos culturales, los idiomas comunes y demás tradiciones es un procedimiento convincente a condición de no hacerlo a partir del presente de los estados nación que integran el continente, o sea desde el punto de llegada de esa historia. Si así se procede, en automático reducimos cualquier indagación de los siglos pasados a la teleología o "final de un cuento" que conocemos de antemano. En un mundo que a muchos ya se nos antoja posnacional, la historia de América no puede ser pensada ni elaborada como la simple adición de historias nacionales, ni siquiera para los siglos XIX y XX. Del legado de Silvio Zavala desprendo la necesidad de emprender la comparación sistemática, no la mera yuxtaposición. A la queja expresada en su momento por el historiador inglés J. H. Parry sobre que en la historia de América no se advertía "prácticamente ninguna narrativa, ningún hilo conductor del desarrollo", 21 respondió ya de manera magistral la obra relativamente reciente del profesor John H. Elliott, en que compara la presencia y la impronta de Gran Bretaña y de España en América entre 1492 y $1830 .{ }^{22}$

Luego de cuantificar la producción de la Revista de Historia de América, Erika Pani ha corroborado que una abrumadora mayoría de artículos corresponden a la América hispana. ${ }^{23}$ No es para menos. Las "Indias Occidentales” fueron el conjunto más vasto, pero también más compacto de reinos y se les asumió como un solo agregado en la Monarquía española. Como tierras de conquista incorporadas a la corona de Castilla de manera accesoria, es decir, en tanto que extensión o parcela de ella, se las percibía, no obstante, de manera un tanto desmembrada a causa de su lejanía. ${ }^{24}$ Fue al cabo del proceso de réplica y asunción del orden jurídico castellano que alcanzaron una densidad muy considerable que desembocó en la denominación Reinos y Señoríos de las Indias, tal y como expresó su propia recopilación de leyes, concluida hacia 1636. Esa expresión se refería tanto a dicho conjunto como a cada una de sus entidades: las sedes respectivas de un virrey en Nueva Espa-

20 Roberto Fernández Castro, "Silvio Zavala y la historiografía americana. Una vida de vínculos intelectuales”, Revista de Historia de América, núm. 155, nueva época, 2018.

21 Frase citada por Erika Pani, "Silvio Zavala y la historia de América. Un juego de escalas", Revista de Historia de América, núm. 155, nueva época, 2018, p. 184.

22 John H. Elliott, Empires of the Atlantic World. Britain and Spain in America 1492-1830, New Haven y Londres, Yale University Press, 2006.

23 Erika Pani, “Silvio Zavala y la historia de América. Un juego de escalas”, Revista de Historia de América, núm. 155, nueva época, 2018, p. 181.

24 En su Discurso político al rey Felipe III al comienza de su reinado (1598) Baltasar Álamos de Barrientos opinaba que a causa de la distancia a la que se hallaban, los estados de las Indias "parecen estar desmembrados de los otros". Referencia tomada de Xavier GIL, La fábrica de la monarquía. Traza y conservación de la Monarquía de España de los Reyes Católicos y los Austrias, Madrid, Real Academia de la Historia, 2016, p. 47. 
ña y el Perú, el Nuevo Reino de Granada, el Reino de Quito, las Capitanías de los reinos de Chile, de Guatemala y aun las del Brasil lusitano incorporado a dicha monarquía entre 1580 y 1640. El jurista Juan de Solórzano Pereyra aportó al respecto una observación perspicaz: dijo que si los reyes hubieran querido añadirlos a su titulatura "todos [esos] reynos y provincias — dijo - no cabrían en muchas ojas y así se han contentado en contraerlos al Plus Ultra de Carlos V o al Hispaniarum et Indiarum Rex de Felipe II”. ${ }^{25}$

Si se me permite, quiero apuntar que desde el Centro de Estudios Históricos de El Colegio de México y de otras instituciones, hemos intentado responder a la vocación internacionalista de la Comisión de Historia del Instituto Panamericano de Geografía e Historia. En 2004 fui invitado por mi amigo y colega de la Universidad de Murcia, José Javier Ruiz Ibáñez, para integrar una nueva y prometedora empresa historiográfica, una red internacional de investigación e investigadores. Fue fundada como una alternativa al enorme desafío impuesto por la renovación historiográfica producida durante los últimos veinte años sobre las monarquías ibéricas de los siglos XVI a XVIII, pero también para responder a los retos impuestos por aquella inmensidad temporal y territorial en el mundo global en que vivimos. La red se llama Columnaria en razón de la divisa del Plus Ultra que ostentaban las armas de Carlos V con las columnas de Hércules en monedas que circularon por todo el orbe, muchas, por cierto, acuñadas en la ciudad de México. En la red hay nodos o equipos de índole territorial, aproximadamente de acuerdo con los antiguos conjuntos de dominios ibéricos; pero, también, nodos temáticos según distintas especialidades: historia política, social, económica o cultural.

Es una propuesta de historia claramente posnacional que nos ayuda a conocer mejor aquel pasado y a evaluar mejor nuestro presente. El camino a recorrer ha sido, es y será largo, de muchas generaciones. El Colegio de México es la cuna del nodo o equipo correspondiente a Nueva España, pero lo integran colegas de nuestra Casa, de la UNAM, de El Colegio de Michoacán y del de San Luis. Como en las monarquías ibéricas la lealtad al soberano como "señor natural" de cada tierra fue proporcional a los lazos que vinculaban a la gente con su patria”, el patriotismo así entendido nos permitió implementar un proyecto sobre rescate y valoración del patrimonio llamado "Vestigios de un mismo mundo..." con una importante financiación durante los años 2008 a 2012. Se actualizaron los acervos bibliográficos y se montaron sub proyectos destinados al rescate de archivos históricos, al

25 Juan Solórzano Pereyra, Política Indiana, Madrid, Fundación José Antonio de Castro, 1996, libro I, cap. 8, n. 16; libro V, cap. 15, n. 6. 
inventario de miles de pueblos de indios, a la identificación de la fiesta como instrumento indispensable para el estudio de las representaciones. Estas realizaciones constan en sendas publicaciones.

Por último debo agregar que en nombre del equipo mexicano de Columnaria se convocó a miembros de otros equipos de la red a las III jornadas de estudio para ponernos al día acerca de las modalidades de incorporación territorial de los dominios europeos, americanos y asiáticos a las Monarquías de España y Portugal. Tuvieron lugar en El Colegio de México en septiembre de 2007 y sus actas también fueron publicadas. ${ }^{26}$ En noviembre de 2019, en concierto con el Instituto de Investigaciones Históricas de la UNAM volveremos a ser sede, ahora de las XV Jornadas Internacionales de Estudio de la Red. Esta vez nos proponemos lograr una mirada del conjunto de los dominios del Nuevo Mundo tanto desde las representaciones de sus actores como desde aquéllas de individuos y grupos ubicados en las posesiones no americanas, de manera entrecruzada, de ahí que aspiremos a hacer surgir un "Espejo de las Indias”.

De lo aquí dicho concluyo que la trayectoria y la obra de Silvio Zavala son elocuentes de una vocación profunda por el hispanismo así de índole historiográfica como literaria es decir, humanística. Esto último lo corrobora la Nueva Revista de Filología Hispánica que encontró cobijo en El Colegio de México a partir de 1947, dando en seguida lugar al segundo centro de esa Casa, el de Estudios Lingüísticos y Literarios. Desde luego que por hispanismo no me refiero a la ramplonería ideológica que añora tiempos idos de monarquía o de dictaduras integristas. No, se trata de un subsuelo histórico de tiempos largos poblado por enlaces, vínculos, circulaciones, ritmos e intercambios de individuos, grupos, saberes y objetos ubicados en muy diversas latitudes y que es preciso restituir con una nueva mirada. Una mirada para la cual los cortes históricos convencionales son cada vez más estorbosos. Requerimos, por ejemplo, de una Edad "Media” que lo sea cada vez menos y que nos ayude a releer los procesos del siglo XVI temprano que, no por haber transcurrido en el Nuevo Mundo resultan menos legítimos que los peninsulares en términos tanto de continuidad como de ruptura.

Hago aquí votos para que la tradición hispanoamericanista de Silvio Zavala y su obra nos siga inspirando para dar con explicaciones serenas que, aunque parezcan "inútiles", estén abiertas al mundo; pero, sobre todo, que

26 Óscar Mazín y José Javier Ruiz Ibáñez (eds.) Las Indias Occidentales. Procesos de incorporación territorial a las Monarquías ibéricas, México, El Colegio de México, Red Columnaria, 2012. 
nos hagan tomar la debida distancia del acecho de cualquier inmediatismo presentista y fanático que quiera o que intente arrebatar respuestas fáciles y, por lo mismo, chatas, superficiales. Muchas gracias por su paciencia y atención. 